\title{
ABORDAGEM DE VERIFICAÇÃO NO ENSINO DE CIÊNCIAS: FORMANDO SOLUÇÕES NAS AULAS DE QUÍMICA
}

\author{
Apresentação: Comunicação Oral \\ José Geovane Jorge de Matos ${ }^{1}$; Lillyane Raissa Barbosa da Silva ${ }^{2}$; Renata Joaquina de \\ Oliveira Barboza ${ }^{3}$; Fernando Cleyton Henrique de Mendonça da Silva ${ }^{4}$; Magadã Marinho \\ Rocha de Lira ${ }^{5}$
}

\section{Resumo}

A abordagem de verificação no Ensino de Ciências expressa suas limitações e possibilidades a respeito do momento ao qual está sendo realizada, dependendo primordialmente de fatores como conhecimento do manuseio de materiais, caracterizando - se pelo seguimento do roteiro experimental sob a orientação do professor. A formação de soluções de diferentes sais de concentrações definidas caracteriza-se pela a utilização da abordagem de verificação, pois há o envolvimento dos discentes na realização do experimento em questão através de um roteiro fechado e estruturado. Antes da aplicação de qualquer atividade experimental se faz necessário resgatar, recapitular ou introduzir conceitos microscópicos valorizando os conhecimentos prévios dos alunos, peça fundamental na construção do saber e na compreensão dos fenômenos químicos. Na construção de soluções é preciso entender o como e por que ocorre a dissolução, a dissociação, a ionização, a solvatação dos íons, para isso o conhecimento acerca das forças intermoleculares, da regra "igual dissolve igual ", bem como a compreensão da termodinâmica é também indispensável nesse processo e esses conteúdos podem ser apresentados antes da atividade experimental. O conceito de solução é pertinente no físico - química que enfatiza os cálculos de concentrações. As participações dos alunos nas etapas da experimentação sob supervisão do docente foram apontadas pelos alunos da Educação Básica como principais fatores na aprendizagem em química. O presente trabalho se viabilizou através das intervenções realizadas pelos bolsistas PIBID - IFPE, no qual tiveram por finalidade investigar a importância na interligação entre a experimentação contextualização, eixos metodológicos necessários no contribuir, no despertar, no motivar, na criatividade, no trabalho em equipe, no aprimorar a capacidade de observação, na capacidade de manipulação de materiais e vidrarias, na capacidade de elaborar hipóteses e propor possíveis soluções.

Palavras-Chave: Soluções de Substâncias, Experimentação, Contextualização.

\footnotetext{
${ }^{1}$ Graduando de Licenciatura em Química, Instituto Federal de Educação, Ciência e Tecnologia de Pernambuco IFPE Campus Vitória de Santo Antão, geomatosofc@gmail.com

${ }^{2}$ Graduando de Licenciatura em Química, Instituto Federal de Educação, Ciência e Tecnologia de Pernambuco IFPE Campus Vitória de Santo Antão, lillyane_raissa@hotmail.com

${ }^{3}$ Graduando de Licenciatura em Química, Instituto Federal de Educação, Ciência e Tecnologia de Pernambuco IFPE Campus Vitória de Santo Antão, renata_joaquina@hotmail.com

${ }^{4}$ Graduando de Licenciatura em Química, Instituto Federal de Educação, Ciência e Tecnologia de Pernambuco IFPE Campus Vitória de Santo Antão, silva.fchm@gmail.com

${ }^{5}$ Mestrado em Educação, Universidade Federal de Pernambuco UFPE, magada.lira@vitoria.ifpe.edu.br
} 


\section{Introdução}

As atividades experimentais de verificação, como sugere o próprio nome, são aquelas empregadas com a finalidade de se verificar ou confirmar alguma lei ou teoria (OLIVEIRA, 2010). Como outras abordagens experimentais, a verificação tem suas possibilidades e limitações a respeito do momento ao qual está sendo realizada, dependendo de fatores como conhecimento do manuseio de materiais, caracterizando - se pelo seguimento do roteiro experimental sob a orientação do professor. A verificação no Ensino de Ciências promove a motivação dos discentes através da solicitação de atividades descritivas, modificações no experimento, observação dos fenômenos e nas possíveis explicações e discussões.

A não-contextualização da química pode ser responsável pelo alto nível de rejeição do estudo desta ciência pelos alunos, dificultando o processo de ensino-aprendizagem (LIMA et al, 2000). A não contextualização dos assuntos de Química pode ser considerado um dos fatores de rejeição dos alunos por essa Ciência, pois os discentes não percebem nenhum sentido inerente a essa disciplina. A experimentação associado à contextualização é um dos recursos metodológicos e pedagógicos utilizados pelos professores com a intenção de melhorar ou contribuir no processo de ensino - aprendizagem. Antes de estabelecer uma aula experimental se faz necessário a introdução e a recapitulação de conceitos químicos, valorizando os conhecimentos prévios dos alunos e contextualizando com situações e fenômenos cotidianos.

Há consideração bastante difundida de que a química é uma ciência presente no cotidiano, ao mesmo tempo, é bem sabido que os estudantes enfrentam sérias dificuldades na aprendizagem dos conteúdos químicos, o que parece ser uma contradição, dado o caráter 'cotidiano' da matéria (ECHEVERRÍA, 1996). A temática de soluções é bastante difundida no nosso dia a dia, o café, o suco, o ar que respiramos, as ligas metálicas são exemplos cotidianos de soluções, presentes na físico-química do Ensino Médio, é relevante que os discentes saibam em nível microscópicos os conceitos básicos como: dissociação, ionização, misturas homogêneas e heterogêneas, solubilidade, solvatação dos íons, forças intermoleculares, determinação de concentrações, para que se possa compreender o como e porquê ocorre a formação de soluções.

O entendimento das relações entre aprendizagem dos conceitos e os fenômenos da realidade se torna efetiva quando o discente reconhece a química na sua vida através da 
percepção da aplicação das ciências no cotidiano. A contextualização se configura no sentido de colaborar na construção do conhecimento a partir das experiências do aluno e o professor é o orientador no processo de ensino. O presente trabalho foi realizado numa Escola Técnica Estadual situada no município de Gravatá/PE, com a intenção de verificar a funcionalidade da Abordagem de Verificação na obtenção dos conhecimentos químicos. Onde foi aplicado um questionário semiestruturado com os respectivos estudantes. A partir da referida iniciativa procura-se propor aos docentes criarem meios que busquem facilitar o entendimento dos conceitos da química e suas características especificas na leitura de mundo e interpretação das práticas cotidianas por meio da visão da ciência.

\section{Fundamentação Teórica}

A abordagem de verificação no Ensino de Ciências é uma maneira de apresentar os experimentos, ao qual expressa suas possibilidades e limitações referentes ao papel do professor, papel do aluno, roteiro de atividade experimental, posição ocupada na sala, algumas vantagens e desvantagens. Um experimento que pode usar esse tipo de abordagem através do roteiro é o da construção ou formação de soluções de diferentes sais, onde os discentes participam ativamente de todas as etapas da experimentação, propondo o professor questionamentos, discussões e reflexões acerca do fenômeno observado. É um trabalho em conjunto que pode emergir diferentes opiniões e explicações cientificas a partir das possíveis alterações no experimento, como consequência novas ideias e conclusões serão generalizadas pelos alunos.

Oliveira (2010) afirma que:

A abordagem de verificação no Ensino de Ciências auxilia pedagogicamente em alguns aspectos positivos como: a solicitação de atividades descritivas relacionada à observação e a possível explicação cientifica do fenômeno analisado, isso desperta a capacidade de expressar coerentemente a teoria e a prática, propor modificações nos experimentos realizado, sugerindo aos discentes respostas e questionamentos diante das possíveis alterações sofridas pelo fenômeno, testar se as hipóteses elaboradas pelos alunos sobre dados fatos está coerente ou não, isso permite a identificação de variáveis experimentais, comparar os resultados com os diferentes grupos na intenção de discutir as divergências existente e a partir daí procurar generalizações.

Torna-se necessário nessa perspectiva experimental a solicitação de relatórios e aplicação de questionários como instrumentos de aprendizagem. O relatório permite ao aluno o contato com a linguagem cientifica, mas antes dessa solicitação é conveniente que o professor disponibilize a estrutura do texto e explique. Vários alunos perceberam a 
importância das aulas experimentais na contribuição do processo de Ensino como: a motivação, a criatividade e o despertar a atenção, o desenvolvimento da capacidade em trabalhar em equipe, o aprimorar a capacidade de observação e registros de informações, o aprender a analisar variáveis e elaborar hipóteses para dados fenômenos, o aprender conceitos científicos, o compreender o papel do cientista na investigação, o aperfeiçoar a capacidade manipulativa, o entender a relação entre ciência, sociedade e tecnologia.

Hoje, considera-se que nas soluções ocorram interações entre as partículas (moléculas ou íons) do soluto (componente em menor quantidade ou substância dissolvida) com as do solvente (componente mais abundante ou agente da dissolução). Dessa forma, as forças eletrostáticas (interatômicas e intermoleculares), que permitem interações entre as partículas de soluto e entre as de solvente, devem dar lugar a novas interações soluto/ solvente quando da formação de uma solução (CARMO; MARCONDES, 2008).

A formação de soluções requer técnicas e procedimentos laboratoriais, e neste sentido a atividade de verificação propicia a aprendizagem do manuseio dos materiais, bem como a aplicação de teorias, hipóteses, definições e conceitos vistos em sala de aula nos fenômenos macroscópicos presentes no cotidiano. No caso da formação de soluções é pré-requisito saber o como ocorre a dissolução e o porquê acontece tal fenômeno físico, para isso o conhecimento acerca das forças intermoleculares, da regra "igual dissolve igual", o entendimento dos conceitos da termodinâmica referente a energia livre de Gibbs, entalpia e entropia é indispensável nesse processo.

Segundo Santos (1999), os professores atribuem às atividades experimentais o caráter motivador no sentido de aumentar a capacidade de aprendizado dos discentes através do envolvimento nos temas da ciência em pauta. O eixo metodológico da experimentação nas diferentes abordagens contém no contexto da química, possibilidades de despertar a curiosidade e maior participação dos discentes no universo da Química, permitindo incentivar a criatividade e interesse pelas Ciências.

\section{Metodologia}

Este estudo apresenta um fragmento obtido na realização de uma investigação de caráter qualitativo realizado numa Escola Técnica Estadual do município de Gravatá/PE através da intervenção do PIBID sobre experimentação no Ensino de Química. As formações de soluções de Sulfato de Cobre de concentrações definidas pelo roteiro foram executadas pelos próprios alunos através de uma abordagem de verificação no Ensino de Ciências. Essa atividade experimental consistiu basicamente na entrega de um roteiro fechado e estruturado 
ao qual continham os procedimentos e materiais necessários a realização do experimento, bem como contendo uma tabela formada de informações sobre a concentração da solução, o volume e a massa a ser encontrada através da fórmula dada no roteiro, as concentrações que foram utilizadas são de $10 \mathrm{~g} / \mathrm{L}, 20 \mathrm{~g} / \mathrm{L}$ e $30 \mathrm{~g} / \mathrm{L}$ de Sulfato de cobre (II) em 100mL de solução. Esse reagente foi usado por conta de sua cor característica que é o azul e para mostrar o aumento da intensidade da cor azul à medida que a concentração aumenta.

A turma foi dividida em dois momentos, uma parte ficou na sala de aula com o professor e a outra parte no laboratório, formamos 6 grupos de 5 alunos, cada grupo responsável em conjunto pela construção de soluções com o Sulfato de cobre (II). Os alunos utilizaram jalecos, óculos de segurança e luvas como equipamentos de proteção. Sob a orientação dos bolsistas PIBID - IFPE ao qual disponibilizaram os seguintes materiais na bancada do laboratório: 4 balões volumétricos de 100mL, 1 pisseta, 1 balança analítica, 4 funis, 4 papéis de filtro, 2 espátulas e 4 béqueres de 250mL. Essa atividade experimental teve por finalidade contribuir no entendimento dos discentes com relação ao significado químico e físico do termo concentração de solução e o como fazer uma solução de um dado reagente na prática

Como instrumento de coleta de dados foi utilizado um questionário ao qual foi aplicado após a atividade experimental, com três perguntas abertas, referentes à experimentação/ contextualização no ensino e uma pergunta fechada sobre o cálculo de concentração $(\mathrm{g} / \mathrm{L})$ que foram respondidas por 30 estudantes do Segundo Ano do Ensino Médio, com o objetivo de analisar a contribuição da Abordagem de Verificação no processo de ensino - aprendizagem.

Figura 1: Materiais usados na formação de soluções. Fonte: Elaborada pelo autor.

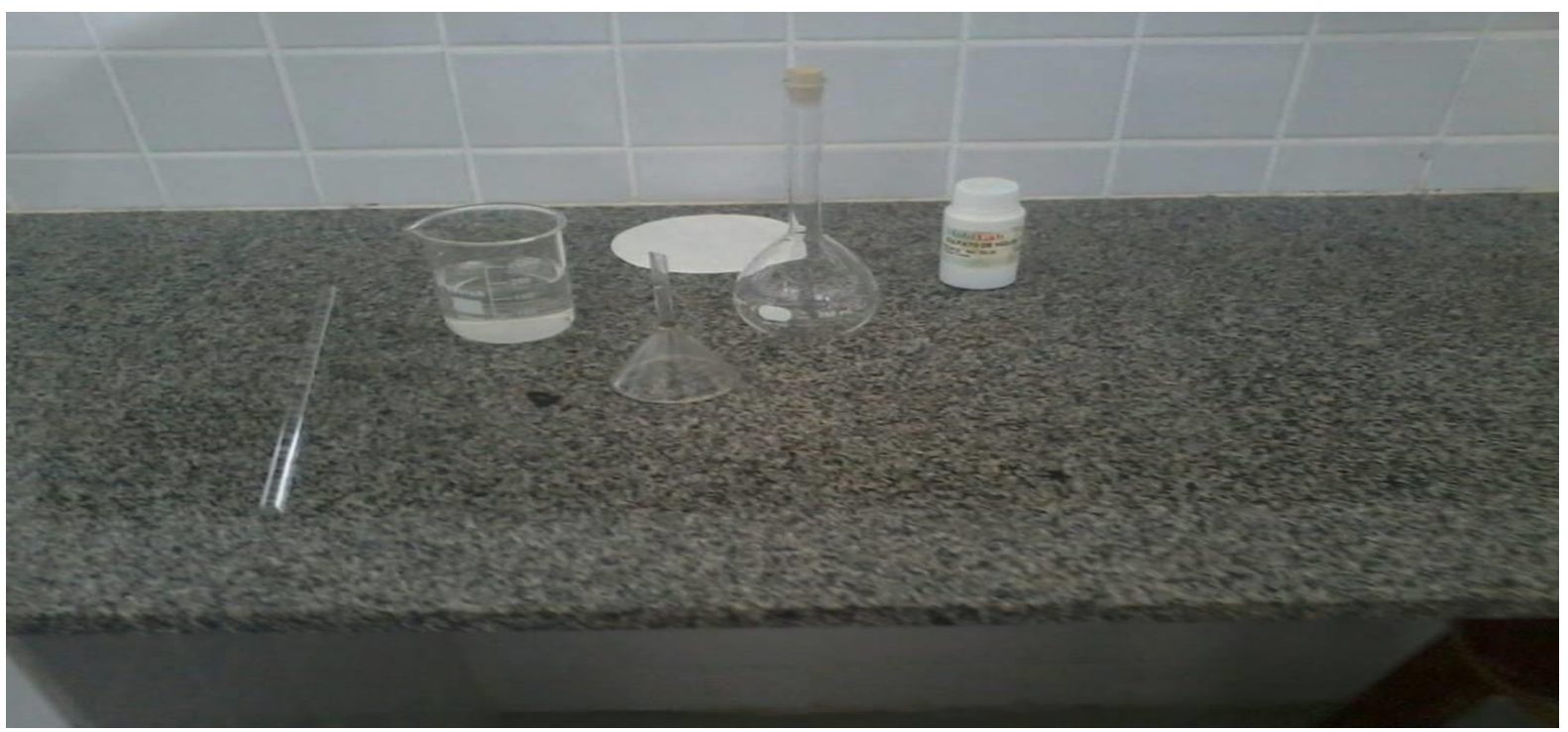


Figura 2: Soluções de concentrações diferentes de Sulfato de Cobre (II). Fonte: Elaborada pelo autor.

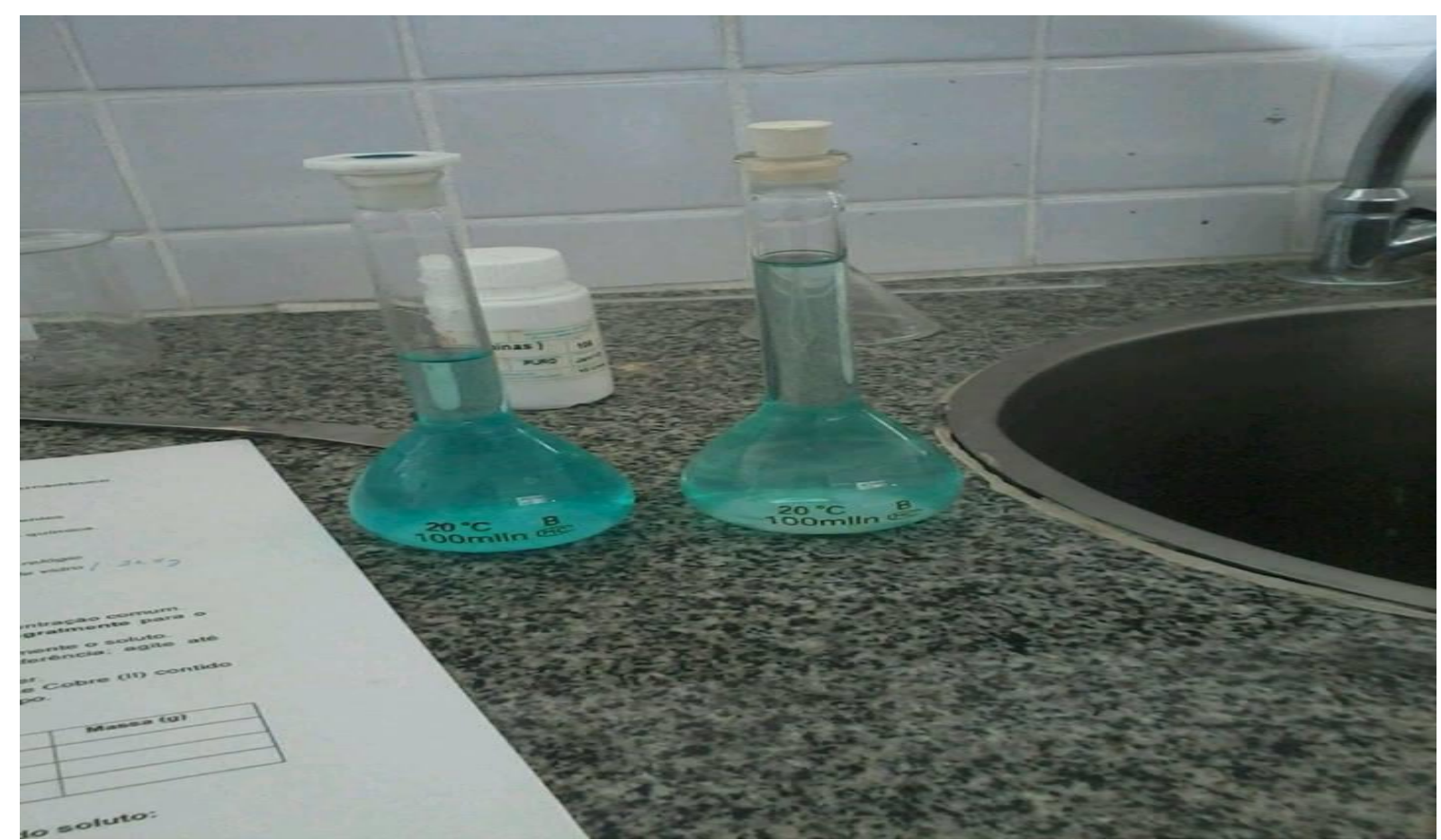

\section{Resultados e Discussão}

Os resultados da pesquisa estão fornecidos no seguinte gráfico, construído a partir da investigação sobre a importância da abordagem de verificação no Ensino de Química. Cada conjunto de colunas representam perguntas do questionário de pesquisa com o percentual de alunos que justificaram e não justificaram seus argumentos.

Gráfico 1. Fonte: Elaborada pelo autor.

\section{QUESTIONÁRIO DE PESQUISA}

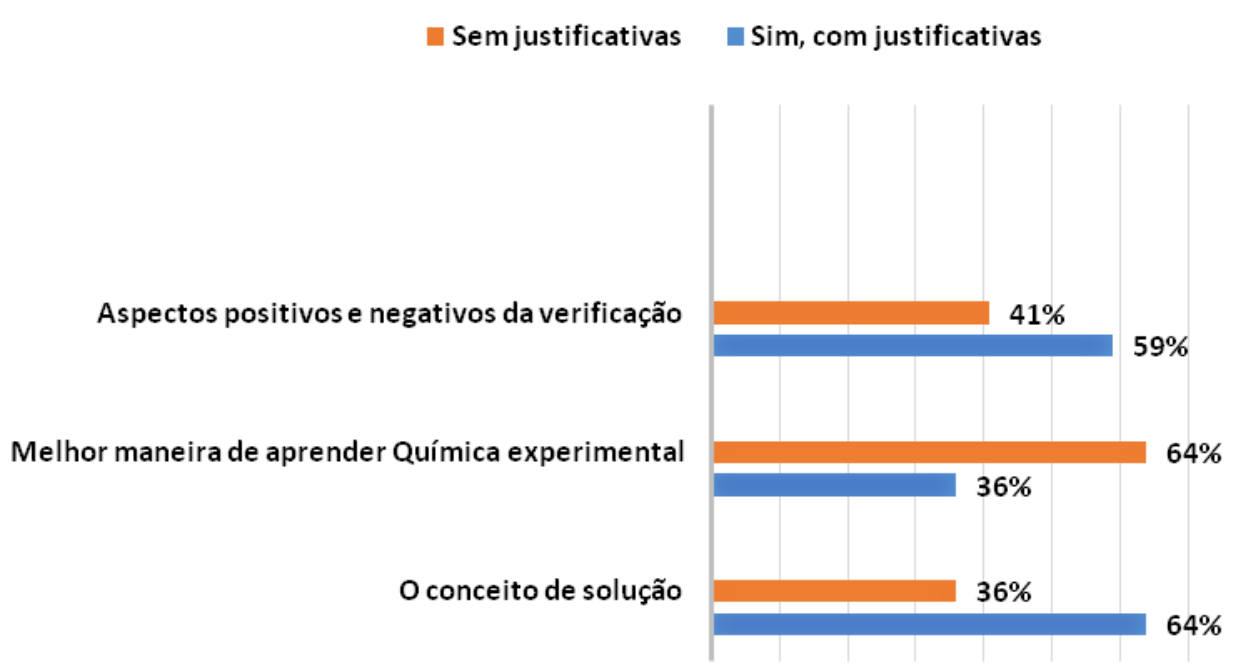

$0 \% \quad 10 \% \quad 20 \% \quad 30 \% \quad 40 \% \quad 50 \% \quad 60 \% \quad 70 \% \quad 80 \% \quad 90 \% 100 \%$ 
O conceito de solução: procura obter definições acerca da temática solução, a partir dos conhecimentos prévios dos alunos, fundamentando esse conceito para uma visão da química, $64 \%$ dos alunos justificaram e exemplificaram as suas respostas.

Os alunos argumentaram:

"São misturas homogêneas (apresentam uma única fase) e possui dois componentes; soluto (o que dissolve e solvente (que é dissolvido), exemplo: água e sal; refrigerante, o ar e etc."

"A uma mistura homogênea entre duas ou mais substâncias damos o nome de solução. Exemplo: refrigerante; água e etc."

"A mistura de componentes químicos para se chegar a uma certa conclusão. Exemplo: a mistura de água com sal. ”

Analisamos diversidades nas respostas percebemos que 36\% dos alunos não justificaram. Os discentes definiram a temática solução a através de conhecimentos adquiridos na escola e na vivencia diária, pois percebe-se respostas mais refinadas e com exemplificações ligados as misturas de soluções presentes no cotidiano ao qual citaram o exemplo mais comum da água e do cloreto de sódio. Antes de estabelecer uma aula experimental é necessário recapitular, resgatar e valorizar os conhecimentos prévios, contextualizando os conceitos de Química para facilitar o processo de Ensino.

Melhor maneira de aprender Química experimental: analisa a abordagem experimental (verificação e demonstração), que de acordo com a opinião dos alunos mais contribuem no processo de aprendizagem, ao quais $36 \%$ justificaram as suas respostas.

Os alunos mencionaram:

"Na minha opinião a melhor maneira é a função do professor executando o experimento e o aluno participando também. “ 
"Com os alunos participando, se torna mais fácil de aprender química, não basta teoria é preciso também prática”.

"A função dos dois, o professor auxiliando o aluno, e ele por sua vez participando do experimento."

Através dos dados investigados constatamos que as opiniões dos alunos são semelhantes e em alguns casos divergentes em relação às abordagens experimentais, mas percentualmente a maior parte dos discentes ressaltou a importância da relação entre discente - docente na experimentação, os experimentos mais dinâmicos, participativos sob orientação ou auxilio do professor é mais significativo no processo de Ensino. 64\% não opinaram sobre a pergunta do questionário.

Aspectos negativos e positivos da verificação: se refere ao ponto de vista do discente com relação aos aspectos negativos e positivos do próprio aluno realizar o experimento sob a supervisão do professor. Ao quais 59\% justificaram suas respostas.

Os alunos explicaram:

“Ele aprende de forma descontraída, mas é perigoso dependendo do momento. “

"Positivos: iremos aprender mais, pois estaremos fazendo. E negativo: não participando das aulas, e não fazer a parte prática. “

"Positivos: melhor envolvimento do aluno, o experimento ajuda o aluno a ter foco no assunto. Negativos: não existem. “

Conclui-se que os alunos mencionam mais aspectos positivos inerente a abordagem de verificação no Ensino de Ciências em relação os aspectos negativos. Os pontos positivos no sentido de melhorar o envolvimento, a participação, a observação e o manuseio de materiais. Citaram alguns pontos negativos como: a não atenção, as brincadeiras em laboratórios e os acidentes possíveis. Assim como as outras abordagens experimentais, a verificação tem suas 
possibilidades e limitações no sentido da disponibilidade do professor, o tempo decorrido para a realização do experimento, os conhecimentos prévios no uso das vidrarias e etc. $41 \%$ não justificaram a resposta.

\section{Concentração de Solução —CORRETA $\square$ SEM RESPOSTA —INCORRETA}

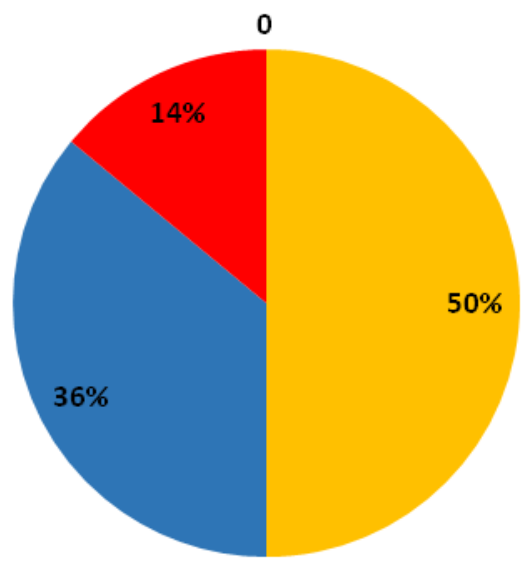

Esse gráfico mostra o percentual de erros, acertos e a não resolução através de uma questão que utiliza o cálculo da concentração comum, percebe - se que 50\% dos discentes responderam corretamente à questão, $36 \%$ não respondeu e $14 \%$ responderam incorretamente. Ocorreram dificuldades dos alunos nas operações básicas da matemática, essa complicação foi principalmente visível no uso das unidades de concentração, volume, massa e na conversão das unidades. Na abordagem de verificação caracteriza pela confirmação de uma lei ou teoria, bem como a introdução de conceitos. Através da porcentagem envolvida no gráfico, $50 \%$ dos discentes conseguiram resolver corretamente a questão na determinação do cálculo de concentração, isso significa a contribuição dessa atividade experimental na aplicação de fórmulas e conceitos vistos nas intervenções do PIBID. É preciso ressaltar a importância no uso das ferramentas da Matemática em Química, já que percebemos dificuldades no uso da fórmula de concentração, nas conversões de unidades e nas operações básicas. Portanto intervenções do PIBID que faça a interdisciplinaridade da Química com a Matemática se fazem necessário na promoção da aprendizagem. 
No primeiro gráfico ocorre alternância percentual das respostas justificadas e não justificadas, com intuito de compreender a opinião dos discentes sobre o papel dos experimentos com abordagem de verificação e a contextualização como eixo metodológico possibilitando a vivencia prática dos conceitos ao cotidiano dos alunos. Analisando os achados investigativos podemos considerar aspectos positivos em relacionar a experimentação e a contextualização na aprendizagem.

O segundo gráfico está baseada numa questão objetiva e aberta sobre cálculo de concentração comum, semelhante ao de um vestibular tradicional, ao qual percentualmente cerca de $50 \%$ dos discentes acertaram a questão. Percebemos que houve dificuldades dos discentes no uso da fórmula e na conversão de unidades, principalmente na utilização das fermentas da Matemática em Química, logo se faz necessário intervenções interdisciplinares usando a abordagem dos conceitos e aplicações da Matemática em Química. Após a intervenção utilizando a abordagem de verificação na formação de soluções de concentrações determinadas pelo roteiro experimental, percebemos o melhor entendimento dos discentes em compreender o significado dos cálculos de concentrações e das unidades envolvidas, bem como fundamentar os conceitos de química a respeito da temática solução.

\section{Conclusões}

Podemos concluir a partir da análise desses achados investigativos que a Abordagem de Verificação no Ensino de Ciências proporciona significativamente a relação participativa, dinâmica entre docente - discente através de reflexões, questionamentos, divergências de ideias no sentido de estabelecer não apenas a confirmação de leis, teorias e conceitos, mas também a construção do saber científico valorizando as experiências prévias dos alunos em função de mudanças no experimento, bem como relacionar a experimentação e contextualização na contribuição desses eixos metodológicos no despertar, no motivar, na criatividade, no trabalhar em grupo, na capacidade manipulativa, na capacidade de elaborar hipóteses, propor soluções e no papel do cientista em interligar ciência, sociedade e tecnologia.

\section{Referências}

CARMO, M. P. E; MARCONDES, M. E. R. Abordando soluções em sala de aula - uma experiência de Ensino a partir das idéias dos Alunos. Química Nova na Escola, n. 28, p.3741 maio 2008.

Disponível em: 
http://webeduc.mec.gov.br/portaldoprofessor/quimica/sbq/QNEsc28/09-AF-1806.pdf Acesso em: 15 set. 2016.

ECHEVERRÍA, A. R. Como os estudantes concebem a formação de soluções. Química Nova na Escola. São Paulo, n. 3, p. 15 - 18, maio 1996. Disponível em: < http://qnesc.sbq.org.br/online/qnesc03/aluno.pdf >. Acesso em: 16 set. 2016.

GIORDAN, M. O papel da experimentação no ensino de ciências. Química Nova na Escola. São Paulo, n. 10, p. 43 - 49, nov. 1999. Disponível em: < http://qnesc.sbq.org.br/online/qnesc10/pesquisa.pdf >. Acesso em: 17 set. 2016.

LIMA, J. F. L. et al. A contextualização no Ensino de Cinética Química. Química Nova na Escola, São Paulo, n. 11, p. 26 - 29, maio 2000. Disponível em: < http://qnesc.sbq.org.br/online/qnesc11/v11a06.pdf >. Acesso em: 17 set. 2016.

OLIVEIRA, J. R. S. Contribuições e Abordagens das Atividades Experimentais no Ensino de Ciências: reunindo elementos para a prática docente. Acta Scientiae (ULBRA), São Paulo, v. 12, n. 1, p. 139-153, jan./jun. 2010. Disponível em: < http://w3.ufsm.br/laequi/wpcontent/uploads/2015/03/contribui\%C3\%A7\%C3\%B5es-e abordagens-de-atividadesexperimentais.pdf >. Acesso em: 18 set. 2016. 